\title{
MELATIH SIKAP SABAR KEPADA ANAK USIA DINI MELALUI KEGIATAN MENGGUNTING
}

\section{Meri Trisnawati ${ }^{1,}$ Nurlaila Wahidah Faujiah ${ }^{2,}$ Eva Rahmawati $^{3,}$ Ridwan Nurhadi $^{4}$ Elfan Fanhas Fatwa Khomaeny.}

\author{
${ }^{1.5}$ Universitas Muhammadiyah Tasikmalaya \\ merytrisnawati8@gmail.com ${ }^{1}$, wahidahnurlailafauziah@gmail.com², \\ evarahmawati330@gmail.com ${ }^{3}$, ridwan.kodoy@gmail.com, ${ }^{4}$ elfan.fanhas@umtas.ac.id ${ }^{5}$,
}

\begin{abstract}
ABSTRAK
Anak usia dini adalah individu yang sedang mengalami proses pertumbuhan dan perkembangan yang pesat bahkan dikatakan sebagai lompatan perkembangan karena itu usia dini dikatakan sebagai golden age (usia emas) yaitu usia yang berharga dibanding usia selanjutnya. Usia tersebut merupakan fase kehidupan yang unik dengan karakteristik khas, baik secara fisik, psikis, sosial, dan moral (Rianto,2004:69). Usia dini / pra sekolah merupakan kesempatan emas bagi anak untuk belajar. Pembinaan pada pendidikan anak usia dini merupakan bagian terpenting dalam memaksimalkan kemampuan dan potensi anak, serta dapat memanfaatkan masa golden age sebagai masa pengarahan, pembimbingan dan pembentukan karakter anak usia dini. Berkaitan dengan hal tersebut, maka peranan guru sangat penting dalam menentukan pencapaian terhadap pembelajaran yang berlangsung di kelas, seperti halnya didalam melatih sikap sabar kepada anak. Dalam melatih sabar anak digunakan metode demonstrasi, proses penerimaan siswa terhadap pelajaran akan lebih berkesan secara mendalam, sehingga membentuk pengertian dengan baik dan sempurna juga siswa dapat mengamati guru selama proses pebelajaran berlangsung. Adapun penggunaan metode demonstrasi mempunyai tujuan agar siswa mampu memahami tentang cara melakukan sesuatu, mengatur atau menyusun sesuatu, misalnya kegiatan menggunting guru mempraktekan secara detail kemudian sisiwa mempraktekannya.
\end{abstract}

Kata Kunci : melatih sikap sabar; anak usia dini (AUD); kegiatan menggunting

\section{ABSTRACT}

Early childhood is an individual who is experiencing the process of rapid growth and development even said to be a leap of development because it is said early age as golden age (golden age) is a valuable age than the next age. The age is a unique life phase with distinctive characteristics, both physically, psychologically, socially, and morally (Rianto, 2004: 69). Early age / pre-school is a golden opportunity for children to learn. Guidance on early childhood education is the most important part in maximizing the ability and potential of children, and can utilize the golden age as a period of guidance, coaching and character formation of early childhood. In this regard, the role of teachers is very important in determining the achievement of learning that takes place in the classroom, as well as in exercising patience to the child. In the practice of patient patience is used demonstration method, the process of acceptance of students to the lesson will be more memorable in depth, so as to form a good and perfect understanding also students can observe the teacher during the process of learning takes place. The use of demonstration methods have a purpose so that students are able to understand about how to do something, organize or arrange something, for example, the activity of cutting the teacher to practice in detail and then putting it into practice.

Keywords: practice patience; early childhood (AUD); cutting activity

\section{PENDAHULUAN}

Pendidikan memiliki dua tujuan, yaitu membimbing para generasi muda untuk menjadi cerdas dan memiliki perilaku berbudi (Lickona, 2015:7). pendidikan keluarga menurut ajaran 
Meri Trisnawati, Nurlaila Wahidah Faujiah. Eva Rahmawati, Ridwan Nurhadi, Elfan Fanhas Fatwa Khomaeny. MELATIH SIKAP SABAR KEPADA ANAK USIA DINI MELALUI KEGIATAN MENGGUNTING. Early Childhood Vol. 2 No. 1, Mei 2018

Islam sebagaimana tertuang dalam Q.S. Lukman 13-19, adalah : Mengenalkan tentang sang pencipta, Mengenalkan tentang asal usul manusia, Mengajarkan ilmu pengetahuan sebagai landasan argumentasi, Mengenalkan hukum kausalitas, Melatih dan membiasakan sholat, Melatih dan membiasakan beramar maruf nahi munkar, Melatih kesabaran, Melatih kepedulian kepada sesama, Melatih anak untuk tidak sombong, Melatih anak hidup bersahaja, Melatih anak untuk sopan santun.

Dari 11 point konsep pendidikan al-qur`an, maka point 1 sampai dengan 4 bersifat pengetahuan pada aspek kognitif $(36,36 \%)$, point 5 sampai dengan 6 bersifat praktis pada aspek psikomotor $(18,18 \%)$, sedangkan point 7 sampai dengan 11 yang merupakan ranah sikap pada aspek apektif $(45,46 \%)$ (Khomaeny, 2017 : 5). Anak adalah miniatur orang dewasa (child as miniature adult), anak sebagai pendosa (child as sinful), anak sebagai lembaran kosong (children as blank tablets), anak sebagai tanaman yang bertumbuh (children as growing plants), anak sebagai properti (children as property), dan anak sebagai investasi masa depan (children as investments) (George S Morrison, 2016 : 214-218)

Proses perkembangan manusia secara utuh telah dimulai sejak janin dalam kandungan ibunya dan memasuki usia emas ( the golden age) sampai uaia 6 tahun. Usia $0-6$ tahun, merupakan masa peka bagi anak sehingga para ahli menyebutnya The Golden Age karena perkembangan potensinya mengalami peningkatan yang sangat signfikan. Usia dini / pra sekolah merupakan kesempatan emas bagi anak untuk tumbuh dan berkembang secara optimal. Pembinaan pada pendidikan anak usia dini merupakan bagian terpenting dalam memaksimalkan kemampuan dan potensi anak, serta dapat memanfaatkan masa golden age sebagai masa pengarahan, pembimbingan dan pembentukan karakter anak usia dini.

Berkaitan dengan hal tersebut, maka peranan guru sangat penting dalam menentukan pencapaian terhadap pembelajaran yang berlangsung di kelas, seperti halnya didalam melatih sikap sabar kepada anak. Sabar merupakan suatu kekuatan, daya positif yang mendorong jiwa untuk menunaikan suatu kewajiban. Sabar juga suatu kekuatan yang menghalangi seseorang untuk melakukan kejahatan. Sabar dalam ilmu Tasawuf merupakan suatu keadaan jiwa yang kokoh, sabil, dan konsekuen dalampendirian. Jiwanya tidak tergoyahkan, pendiriannya tidak berubah bagaimana pun beratnya tantanganyang dihadapi. Tujuan penciptaan situasi tersebut agar manusia menggunakan pikiran mereka untuk menyelesaikan masalah dengan cara yang paling disukai Allah, keadaan apapun yang dirasakan manusia, ketika mereka tidak mampu menyelesaikan denganseorang diri, maka yang harus mereka lakukan ialah bersabar dan meyakini bahwa pertolongan Allah akan datang bagi mereka.

Oleh karena itu, kesempatan ini hendaknya dimanfaatkan sebaik baiknya untuk pembelajran anak karena rasa ingin tahu anak usia dini ini berada pada posisi puncak dan tidak ada usia sesudahnya yang menyimpan rasa ingin tahu anak melebihi usia dini, Anak usia dini juga adalah :

1. Titipan dan amanat dari ALLAH SWT

2. Individu yang sedang dalam proses tumbuh kembang dengan sangat pesat

3. Memiliki sejumlah potensi dan kemampuan 
Meri Trisnawati, Nurlaila Wahidah Faujiah. Eva Rahmawati, Ridwan Nurhadi, Elfan Fanhas Fatwa Khomaeny. MELATIH SIKAP SABAR KEPADA ANAK USIA DINI MELALUI KEGIATAN MENGGUNTING. Early Childhood Vol. 2 No. 1, Mei 2018

4. Unik, tetapi secara universal juga memiliki kecenderungan perilaku sesuai dengan usianya.

\section{METODE}

Artikel ini menggunakan metode penelitian Literature review, literature review adalah uraian tentang teori, temuan, dan bahan penelitian lainnya yang diperoleh dari bahan acuan untuk dijadikan landasan kegiatan penelitian untuk menyusun kerangka pemikiran yang jelas dari perumusan masalah yang ingin diteliti. Literature review merupakan cerita ilmiah terhadap suatu permasalahan tertentu.

Literature review berisi ulasan, rangkuman, dan pemikiran penulis tentang beberapa sumber pustaka (artikel, buku, slide, informasi dari internet, dll) tentang topik yang dibahas.

\section{HASIL DAN PEMBAHASAN Pengertian dan karaktersitik Anak Usia Dini}

Anak usia dini adalah individu yang sedang mengalami proses pertumbuhan dan perkembangan yang pesat bahkan dikatakan sebagai lompatan perkembangan karena itu usia dini dikatakan sebagai golden age (usia emas) yaitu usia yang berharga dibanding usia selanjutnya. Usia tersebut merupakan fase kehidupan yang unik dengan karakteristik khas, baik secara fisik, psikis, sosial, dan moral. Karakteristik Anak Usia Dini :

1. Memiliki rasa ingin tahu yang tinggi Anak usia dini sangat ingin tahu tentang dunia sekitarnya. Pada masa bayi rasa inign tahu ini ditunjukkan dengan meraih benda yang ada dalam jangkauannya kemudian memasukkannya ke mulutnya. Pada usia 3-4 tahun anak sering membongkar pasang segala sesuatu untuk memenuhi rasa ingin tahunya. Anak juga mula gemar bertanya meski dalam bahasa yang masih sangat sederhana.

2. Aktif dan Spontan

Aktif dalam aspek fisikmotoriknya, menggunakan seluruh indera untuk memperoleh pengetahuan. Anak juga spontan dalam merespon lingkungan di sekitarnya.

3. Merupakan pribadi yang unik

Meskipun banyak kesamaan dalam pola umum perkembangan anak usia dini, setiap anak memiliki kekhasan tersendiri dalam hal bakat, minat, gaya belajar, dan sebagainya. Keunikan ini berasal dari faktor genetis dan juga lingkungan. Untuk itu pendidik perlu menerapkan pendekatan individual dalam menangani anak usia dini.

4. Memiliki Daya Imajinasi yang Tinggi

Anak usia dini sangat suka membayangkan dan mengembangkan berbagai hal jauh melampaui kondisi nyata. Bahkan terkadang mereka dapat menciptakan adanya teman imajiner. Teman imajiner itu bisa berupa orang, benda, atau pun hewan.

5. Berada dalam masa paling potensial untuk belajar

Masa itu sering juga disebut sebagai "golden age" atau usia emas. Karena pada rentang usia itu anak mengalami pertumbuhan dan perkembangan yang sangat pesat di berbagai aspek. Pendidik perlu memberikan berbagai stimulasi yang tepat agar masa peka ini tidak terlewatkan begitu saja. Tetapi mengisinya dengan hal-hal yang dapat mengoptimalkan tumbuh kembang anak. 
Meri Trisnawati, Nurlaila Wahidah Faujiah. Eva Rahmawati, Ridwan Nurhadi, Elfan Fanhas Fatwa Khomaeny. MELATIH SIKAP SABAR KEPADA ANAK USIA DINI MELALUI KEGIATAN MENGGUNTING. Early Childhood Vol. 2 No. 1, Mei 2018

6. Berada dalam masa paling potensial untuk belajar

Masa itu sering juga disebut sebagai "golden age" atau usia emas. Karena pada rentang usia itu anak mengalami pertumbuhan dan perkembangan yang sangat pesat di berbagai aspek. Pendidik perlu memberikan berbagai stimulasi yang tepat agar masa peka ini tidak terlewatkan begitu saja. Tetapi mengisinya dengan hal-hal yang dapat mengoptimalkan tumbuh kembang anak.

7. Berada dalam masa paling potensial untuk belajar

Masa itu sering juga disebut sebagai "golden age" atau usia emas. Karena pada rentang usia itu anak mengalami pertumbuhan dan perkembangan yang sangat pesat di berbagai aspek. Pendidik perlu memberikan berbagai stimulasi yang tepat agar masa peka ini tidak terlewatkan begitu saja. Tetapi mengisinya dengan hal-hal yang dapat mengoptimalkan tumbuh kembang anak.

8. Berada dalam masa paling potensial untuk belajar

Masa itu sering juga disebut sebagai "golden age" atau usia emas. Karena pada rentang usia itu anak mengalami pertumbuhan dan perkembangan yang sangat pesat di berbagai aspek. Pendidik perlu memberikan berbagai stimulasi yang tepat agar masa peka ini tidak terlewatkan begitu saja. Tetapi mengisinya dengan hal-hal yang dapat mengoptimalkan tumbuh kembang anak.

\section{Pengertian Sabar}

Kata shabar diambil dari dari kata yang terdiri dari huruf shad, ba' dan ra'. Maknanya berkisar pada tiga hal yaitu menahan, ketinggian sesuatu, dan sejenis batu. Dari makna menahan lahirlah makna konsisten, mampu bertahan, karena yang mampu bertahan menahan pandangannya pada satu sikap. Dari ketiga makna tersebut saliing keterkaitan apalagi bila pelakunya manusia. Seseorang yang menahan gejolak hatinya dinamai bersabar. Seseorang yang sabar, akan menahan diri, dan untuk itu dia memerlukan kekukuhan jiwa dan mental baja agar dapat mencapai ketinggian yang diharapkannya

Sabar dalam Kamus Besar Bahasa Indonesia berarti tahan menderita sesuatu, tenang tidak tergesa-gesa, tidak pemarah.Dari segi bahasa, sabar berarti menahan dan mencegah, segi istilah sabar adalah menahan diri dari sifat kegundahan dan rasa emosi, menahan lisan dari keluh kesah serta menahananggota tubuh dari perbuatan yang tidak terarah.

Kesabaran merupakan salah satu ciri mendasar orang yang bertaqwa kepada Allah Swt. Bahkan sebagian ulama mengatakan bahwa kesabaran merupakan setengahnya keimanan. Sabar memiliki kaitan yang tidak mungkin dipisahkan dari keimanan.

\section{Pendapat ulama tentang kesabaran}

Ulama membagi kesabaran menjadi tiga hal :

1. Sabar dalam ketaatan kepada Allah.

$$
\text { Merealisasikan ketaatan }
$$

kepada Allah seperti shalat tepat waktu, shalat tahajjud, puasa, dan zikir, membutuhkan kesabaran, karena secara tabiatnya jiwa manusia enggan untuk beribadah dan berbuat ketaatan. Ditinjau dari penyebabnya, 
Meri Trisnawati, Nurlaila Wahidah Faujiah. Eva Rahmawati, Ridwan Nurhadi, Elfan Fanhas Fatwa Khomaeny. MELATIH SIKAP SABAR KEPADA ANAK USIA DINI MELALUI KEGIATAN MENGGUNTING. Early Childhood Vol. 2 No. 1, Mei 2018

terdapat tiga hal yang menyebabkan insan sulit untuk sabar. Pertama karena malas, seperti dalam melakukan ibadah shalat. Kedua karena bakhil (kikir), seperti menunaikan zakat dan infaq. Ketiga karena keduanya, (malas dan kikir), seperti haji dan jihad.

2. Sabar dalam meninggalkan kemaksiatan

Meninggalkan kemaksiatan juga membutuhkan kesabaran yang besar, terutama pada kemaksiatan yang sangat mudah untuk dilakukan, seperti ghibah, dusta, memandang sesuatu yang haram dan sebagainya. Karena kecendrungan jiwa manusia suka pada hal-hal yang buruk dan "menyenangkan" dan perbuatan maksiat identik dengan hal-hal yang "menyenangkan".

3. Sabar dalam menghadapi ujian dan cobaan dari Allah

Seperti sabar menghadapi godaan syaitan dan tidak terjerumus dalam maksiat, sabar ketika mendapat musibah, baik yang bersifat materi ataupun inmateri; misalnya kehilangan harta, kehilangan orang yang dicintai, dan sebagainya.

\section{Aktivitas menggunting}

Menggunting menggunting merupakan kegiatan kreatif yang menarik bagi anak-anak (Sumanto, 2005:108-114). Langkah kerja menggunting :

1. Tahap persiapan, yaitu dengan menentukan bentuk, ukuran, model yang akan dibuat, serta alat pemotong dan warna kertas yang akan digunakan agar terlihat menarik bagi anak.

2. Tahap pelaksanaan, yaitu melakukan pemotongan kertas tahap demi tahap sesuai dengan gambar pola (gambar kerja) dengan rapi sampai selesai.

3. Tahap penyelesaiannya, yaitu menempelkan hasil guntingan diatas bidang gambar dengan rapi yang telah disediakan guru.

Suratno (2005: 126) menyatakan bahwa kegiatan menggunting membutuhkan proses keterampilan menggerakkan otot-otot tangan dan jarijari untuk berkoordinasi dalam menggunting sehingga bisa memotong kertas, kain atau yang lain sesuai yang diinginkan; seperti menggunting yang berpola, menggunting dan melipat untuk membentuk gambar, membentuk pola ataupun yang lain. Mukhtar (2013: 194) mengungkapkan tahapan perkembangan menggunting anak yaitu sebagai berikut:

1. Tahap pra menggunting

Kegiatan yang memperkuat tangan dan genggaman harus dimulai sejak bayi dengan kegiatan anak memungut benda-benda kecil, kegiatan meremas, kegiatan merobek dengan sepenuh tangan dan kegiatan merobek dengan jari.

2. Perkembangan menggunting

Adapun tahapan-tahapan kegiatan menggunting yang dapat dilakukan bagi anak adalah: (1) tahap ke-1 : menggunting sekitar pinggiran kertas, (2) tahap ke-2 : menggunting dengan sepenuh bukaan gunting, (3) tahap ke-3: membuka dan menggunting terus menerus untuk sepanjang kertas, (4) tahap ke-4 : menggunting di antara dua garis lurus, (5) tahap ke-5 : menggunting bentuk tetapi tidak pada garis, (6) tahap ke-6 : menggunting pada garis tebal dengan terkendali, (7) tahap ke7 : Menggunting bermacam-macam bentuk. 
Meri Trisnawati, Nurlaila Wahidah Faujiah. Eva Rahmawati, Ridwan Nurhadi, Elfan Fanhas Fatwa Khomaeny. MELATIH SIKAP SABAR KEPADA ANAK USIA DINI MELALUI KEGIATAN MENGGUNTING. Early Childhood Vol. 2 No. 1, Mei 2018

\section{Prilaku orang yang sedang beraktivitas menggunting.}

Orang yang sedang beraktivitas menggunting, dapat dipastikan menggunakan alat gunting yang tajam, yang digunakan untuk memotong dan atau membentuk pada suatu media. Menggunting perlu konsentrasi tinggi, sehingga gunting dapat memotong media sesuai dengan keinginan penggunting, dan tidak sebaliknya membahayakan diri penggunting.

Selain perlu konsentrasi, orang yang sedang beraktivitas menggunting perlu ketelatenan dan kesabaran, supaya dapat menggunting sesuai dengan pola yang telah ditentukan, tidak keluar pola atau bahkan merusak pola yang telah dibentuk.

Menggunting adalah aktivitas yang menyenangkan bagi anak, karena rasa ingin tahu yang tinggi maka anak akan antusias untuk mencoba menggunakan gunting untuk memotong atau menggunting. Kesenangan dan antusiasme anak akan aktivitas menggunting dapat digunakan oleh guru atau orang tua untuk mendidik anaknya, terutama aspek kesabaran.

Untuk melatih kesabaran pada anak dengan aktivitas yang menyenangkan, dapat menggunakan aktivitas menggunting sebagai metode pembelajaran. Adapun langkah-langkah menggunting yang dapat melatih kesabaran anak, adalah :

1. Siapkan gunting yang aman untuk anak, dan tidak terlalu tajam

2. Siapkan media yang akan digunting oleh anak

3. Beri pola atau gambar pada media

4. Mintalah anak untuk menggunting media sesuai dengan pola atau gambar yang ada
5. Awasi anak dalam menggunakan gunting, dan berilah arahan untuk menggunting dengan baik dan benar.

6. Berilah pujian ketika anak mampu menggunting sesuai dengan pola/ gambar yang ada, dan berilah motivasi apabila anak masih belum bisa menggunting sesuai dengan pola/ gambar yang ada.

\section{SIMPULAN DAN SARAN}

Dari pembahasan di atas dapat disimpulkan bahwa kegitan menggunting dapat meningkatkan sikap sabar pada anak usia dini. Kegiatan menggunting pada anak terjadi melalui berbagai tahapan yaitu (a) tahap ke-1 : menggunting sekitar pinggiran kertas, (b) tahap ke-2 : menggunting dengan sepenuh bukaan gunting, (c) tahap ke-3: membuka dan menggunting terus menerus untuk sepanjang kertas, (d) tahap ke-4 : menggunting di antara dua garis lurus, (e) tahap ke-5 : menggunting bentuk tetapi tidak pada garis, (f) tahap ke-6 : menggunting pada garis tebal dengan terkendali, dan (g) tahap ke-7 : Menggunting bermacam-macam bentuk.

Bagi orang tua dan pendidik harus bisa melatih dan meningkatkan sikap sabar pada anak sejak dini, salah satunya dengan melalui kegiatan menggunting yang diberikan kepada anak pada proses pembelajaran baik di sekolah maupun di rumah. Adapun langkah-langkah menggunting yang dapat melatih kesabaran anak, adalah :

1. Siapkan gunting yang aman untuk anak, dan tidak terlalu tajam

2. Siapkan media yang akan digunting oleh anak

3. Beri pola atau gambar pada media

4. Mintalah anak untuk menggunting media sesuai dengan pola atau gambar yang ada 
Meri Trisnawati Nurlaila Wahidah Faujiah, Eva Rahmawati. Ridwan Nurhadi, Elfan Fanhas Fatwa Khomaeny. MELATIH SIKAP SABAR KEPADA ANAK USIA DINI MELALUI KEGIATAN MENGGUNTING. Early Childhood Vol. 2 No. 1, Mei 2018

5. Awasi anak dalam menggunakan gunting, dan berilah arahan untuk menggunting dengan baik dan benar.

6. Berilah pujian ketika anak mampu menggunting sesuai dengan pola/ gambar yang ada, dan berilah motivasi apabila anak masih belum bisa menggunting sesuai dengan pola/ gambar yang ada.

\section{DAFTAR PUSTAKA}

Khomaeny, Elfan Fanhas Fatwa. The Concept of Family Education According to Q.S Lukman: 13-19. Proceedings of the ICECRS, [S.1.], v. 1, n. 2, apr. 2018. ISSN 2548-6160. Available at: <http://ojs.umsida.ac.id/index.php licecrs/article/view/1427/1014>.

Jaliah, Juliana. Yuline. Hakim, Lukmanul. Upaya meningkatkan sabar menunggu giliran pada anak usia 5 - 6 tahun

Lickona, Thomas. 2015. Educating for Character : How Our Schools Can Teach Respect and Responsibility (Penerjemah Juma Abdu Wmaungo). Jakarta : bumi Aksara.

Lisdarlia. Salwiah. Meningkatkan kemampuan motorik halus anak melalui kegiatan mewarnai, menggunting dan menempel (3M) di TK Mekar Indah kota Kendari. Volume 1, No 1, Maret 2018

Morrison, George S (2016). Pendidikan Anak Usia Dini Saat Ini Edisi 13 (penerj Yudi Santoso). Yogyakarta : Pustaka Pelajar

Mulyasa. 2014. Manajemen Paud. Bandung : PT Remaja Rosdakarya

Raihanan, 2016 . Konsep sabar dalam al qur'an. Volume 6 No 1 Januari Juni
Sumanto, 2005. Pengembangan Kemampuan Sains seni rupa anak TK. Jakarta : Direktur Pembinaan Pendidikan Tenaga Kependidikan dan Ketenagaan Perguruan Tinggi 